\title{
A CLINICAL LECTURE ON SHAKING PALSY.
}

BY THOMAS BUZZARD, M.D., F.R.C.P.

Physician to the National Hospital for the Paralysed and Epileptic.

The disease "Shaking Palsy," or "Paralysis agitans," some examples of which I shall have the opportanity of showing you, was first regularly described by our countryman Parkinson in 1817. Parkinson was a member of the Royal College of Surgeons, and his 'Essay on the Shaking Palsy' presents so graphic and admirable a description of the disease, that comparatively little has been left for subsequent observers to add to his account. In our time Charcot has also made the disease the subject of clinical investigation. The influence of these writers cannot fail to be felt at every turn by any one desirous of demonstrating vthe features of this remarkable affection. Parkinson's definition of Paralysis agitans is as follows :

"Involuntary tremulous motion, with lessened muscular power, in parts not in action and even when supported; with a propensity to bend the trunk forwards and to pass from a walking to a running pace : the senses and intellect being uninjured."

He quotes the distinction between kinds of tremor which was drawn by Sylvius de la Boe, who contrasts tremors produced by attempts at voluntary motion with those which occur whilst the body is at rest. Saurages in 1763 had distinguished the latter species (Tremor coactus) by observing that "the tremulous parts leap and as it were vibrate even when supported ;" whilst every other tremor, he observes, ceases when the voluntary exertion for moving the limb stops, or the part is supported, but returns when we will the limb to move. 
We still depend very much upon this point-the difference of circumstances in which the tremor shows itself, for our diagnosis of Paralysis agitans.

The female patient, Mrs. G., is a widow, æt. 62 . She sits with her chin resting on her chest, the lower lip and the neighbouring muscular structures about the chin being constantly in tremulous movement. There is a frown upon her brows. Her hands lie in her lap, the fingers being somewhat interlaced, apparently for the comfort of mutual support. When separated, the hands chiefly, and the forearms to a less extent, are in a state of constant tremor. If we count the toand-fro movements, we find them to number from 160-170 in the minute. The tremor seems to be about equal in each hand.

When I speak to her and she answers, the shaking of the hands becomes more marked. It is not that the rapidity, however, is increased, but the movements occupy a larger space. My hand placed upon her knees cannot distinguish any trembling of the legs.

She can stand and walk, as you see, without help, but with short, "toddling" steps, the head being carried low and the body stooping forward. The face shows little or no expression, and wears a kind of fixed look. This attitude and general bearing it is very important to note carefully; they are characteristic of the disease. As she stands with her back towards me, if I pull her by the dress, with even the slightest force, she tends to fall backwards. When asked to lay hold of a cup which is offered to her, she puts out her right hand to take it, and whilst doing so the movements entirely cerse. When, however, she has got hold of it and is told to squeeze the handle the movements return.

In another form of shaking palsy, that dependent upon in. sular, or multilocular, or disseminated sclerosis, as it is variously called, "the tremor," as Charcot hrs pointed out, " only manifests itself on the occasion of intentional movements of some extent; it ceases to exist when the muscles are abandoned to complete repose." The cessation of tremor in this woman when she stretches out her hand to take the cup is not an exceptional circumstance. In many cases of Paralysis agitans, it is true, 
the tremor will persist throughout the roluntary movement. But the present feature also is common enough, and has not escaped the observation of Parkinson, who contrasts it with what happens in that which he styles "tremor." "It is necessary to bear in mind," he writes, "that this affection" (shaking palsy) "is distinguishable from tremor by the agitation in the former occurring whilst the affected part is supported and unemployed, and being even checked by the adoption of voluntary motion; whilst in the latter the tremor is induced immediately on bringing the parts into action. Thus an artist afflicted with the malady here treated of, whilst his hand and arm are palpitating strongly, will seize his pencil, and the motions will be suspended, allowing him to nse it for a short period; but in tremor, if the hand be quite free from the affection, should the pen or pencil be taken up the trembling immediately commences."

Charcot, also, when referring to cases of shaking palsy in which the tremor only occurs intermittently, says : "Singularly enough, it is just in such cases that the tremor shows itself rather when the limbs are at rest, and ceases when they are set in motion by the will."

There can be no doubt that in general the persistence of the movements of the hands when the muscles are abandoned to repose, is sufficient to differenciate Paralysis agitans from insular sclerosis. This is a rule, however, which is by no means without exceptions. In one of my cases, which an autopsy showed was an example of insular sclerosis, the tremor occurred as well in a condition of repose as on the occasion of intentional movement; on the other hand, I think I can call to mind more than one case belonging probably to the class of Paralysis agitans in which the tremor was disposed to cease during muscular repose, and evince itself during voluntary movement of the limb.

The attitude of this patient's hands is another very noteworthy feature, and I would ask you to remember it particularly in reference to an examination we shall presently make of the other patient. It is, as Charcot has shown, very much the attitude of the writing hand, the fingers being inclined to an angle of abont $45^{\circ}$ with the metacarpal portion of the 
hand. You will note, however, that the fingers do not present the easy curve seen in the writing hand. Their position, it seems to me, is precisely that which is obtained by faradising the dorsal interossii-the first phalanx is flexed, the second and third being extended upon the first. The tremulous movements of the thumb laterally, as well as backwards and forwards, are marked more strongly than those of the fingers, and conrey the idea of the patient rolling some object between it and the fingers. The fingers, en masse, tend to deviate towards the ulnar side. The extended position of the fingers would seem to indicate a tendency to muscular rigidity as well as convulsion, and this is indeed what we find when we come to examine other parts of the body. It is especially well seen in the fixed position of the head and neck; the chin can be lifted, but it soon resumes its position. We also learn from the patient that she has a great tendency to become cramped in her limbs. This rigidity, as we shall see in the other patient, may become the most dominant feature of the case. When we take an aggregation of symptoms-Symptomen-complex, I think the Germans call it-and give a name to the disease which is characterised by the association of these symptoms, we must take care to remember that in various examples individual symptoms will certainly vary in their prominence. It will often happen that a symptom which perhaps we have thought of but lightly-have "thrown in " among the rest, as it were-will in a certain caso assert itself so strongly as to dwarf those others, upon the presence of which we are accustomed to rely for making a diagnosis. On the other hand, a symptom which we have come to look upon as essential, may be actually absent. In this woman the presence of the peculiar tremor of the hands must be allowed to be, as indeed happens in the majority of cases of Paralysis agitans, the most striking feature. I have shown you, also, the slight indication there is of a tendency to rigidity of the muscular system. In her case this is a symptom pronounced only in the most trifling degree. We can readily imagine, however, that this symptom might be the most dominant one in a certain case, and that the tremor in its turn might be absent or only slightly marked. I shall be able to show you presently a man 
who, I think, exhibits this kind of anomaly. Bat for the present let us return to the consideration of the disense of which we have a typical example in the person of this female.

More often than not, I think, the muscles of the face fail to show, to a great extent at least, the tremor which is so marked in the hands, but in this patient there is very distinct tremulous movement of the lips, especially the under lip. And in consequence of this inability to keep the mouth sufficiently closed, the saliva is almost constantly dribbling, much as we see it in cases of glosso-labio-pharyngeal paralysis. There is no difficulty, according to her account, in swallowing.

Mrs. T. suffers much from flushes of heat, and her face is ever and anon covered with a deep blush. In many cases these symptoms are accompanied by profuse general perspiration, but this is not observed in the present instance. An "habitual sensation of excessive heat" was described, for the first time, by Charcot as characterising Paralysis agitans.

There is a symptom in this patient which, according to my experience, is a very frequent one, but which has not hitherto, so far as I know, received attention at the hands of any observer. Charcot, it is true, has described the affection of speech, which is often observed, in these words: "There is no real difficulty of speech, but the utterance is slow, jerky, and short of phrase; the pronunciation of esch word appears to cost a considerable effort of the will. If the tremor of the body be intense, it may happen that the utterance may be tremulous, broken, jolted out, as it were, like that of an inexperienced rider on horseback when the animal is trotting. However, in both crses we should recognise in this a phenomenon of transmitted tremor. Finally, the patients seem to speak between their teeth." We observe something of the kind in this patient, but the symptom upon which I now wish to speak concerns not the articulation bat the voice. The voice has a peculiar "piping" character. It is, if you will observe, the conventional voice of the old man upon the stage. We all know that on the stage peculiarities of every kind are obliged to be accentuated for the sake of strong light and shade. When a very advanced period of old age has to be represented, the tone of voice adopted is exactly of the shrill 
piping character which we note in this woman, who, however, is only sixty-two years of age. Since I first noted this "piping" note in cases of shaking palsy many years ago, I have been interested in observing whether it is common in the exceptionally aged persons (not aftlicted with Paralysis agitans) whom from time to time I have met. I have not found it to be so. Now, Paralysis agitans, although, as Charcot has pointed out, it especially assails persons who have passed their fortieth or fiftieth year, has a slow march and little or no tendency to curtail longevity. Hence there are always about a certain number of persons afflicted with Paralysis agitans who have arrived at a ripe old age, and who present this peculiarity of voice. I cannot help thinking that the conventional voice of age on the stage has originally been derived from the study of some old person affected with this disease, and thence handed down, as we know is the stage custom, to successive generations of performers.

A slight tremulousness shows itself in the patient's tongue. There is no affection of the cutaneous sensibility, nor of the special senses. The bowels are very obstinate, so that she is habitually obliged to take aperient medicine. She can retain the faces, but has to be very quick in relieving her bladder, and requires to get up five or six times every night for the purpose. She suffers pain of an aching character in her limbs.

We do not observe in this patient a symptom which is so common in this disease as often to enable us to recognise a case at a glance. Parkinson describes it as "a propensity to bend the trunk forwards and to pass from a walking to a running pace." Although the patient presents the fixed head and stooping body, she does not hurry along as we so often see in such cases. There is no "festination," to use the term employed to designate this hurried march.

The amount of muscular power varies much in individual instances, and also in different strges of the disease. At first there may be but little notable weakness; but as time goes on, a very distinct loss of power shows itself in the limbs and especially in those affected by tremor. In this woman the power of grasp is only feeble. 
Before proceeding to consider other points connected with the symptoms of this peculiarly distressing disense, let us examine the other patient whom I have brought before you. I am indebted to Dr. Beevor's notes for many particulars of his case.

James H. is 64 years of age. He has been an upholsterer's foreman, has worked hard, and, according to his own account, has always been steady. He has been married 30 years, has had four children, and his wife has never miscarried. There is no history of phthisis, insanity, or fits in his family, but a doubtful account of hemiplegia in his mother. He says that he never had scarlet fever or rheumatic fever, or syphilis. He had "typhns" fever when young, and has suffered a little from gravel. His present illness dates from only two years.

At first he found difficulty in using his knife and fork and in putting on his clothes. About four months later he began to drag his feet in walking, and gradually power was lost more and more completely in all his limbs. Six months ago he began to "speak thick,"according to his own description, and this has since become worse. He has not had trouble in masticating, and could always protrude his tongue. He says that he has sometimes choked in swallowing, but no difficulty has been observed in this respect since his admission into hospital. For six months past he has noticed that when his arms were raised they remained in the acquired position longer than was natural. He has not been able to walk for a year past, or even to get out of bed. His legs and arms have been stiff for the last nine months.

The patient is a very stout old man, who constantly lies in bed without occupying himself in any way. He cannot help himself at all. There is an aspect of marked mental hebetude, or at all events an extreme slowness of expression; so that it is difficult to elicit answers to questions about his history. The difficulty is partly also attendant upon his mumbling speech, which is sometimes quite unintelligible. Yet we contrive to get, in process of time, though the task is laborious, a fair amount of information from him. The face wears a peculiarly stolid expression. When told to show his teeth he makes only a slow and feeble attempt; he can close his eyes, 
but cannot screw his eyelids up tight. The tongue is protrucled strnight although slowly, and it does not show any tremor. Cutaneous sensibility is nowhere affected. The patient has not suffered from pains in his head or body. The movements of the eye-muscles are natural. There is no nystrigmus.

The upper extremities are thin in proportion to the lower, but the emaciation, if so it can be called, is symmetrical on the two sides, as is shown by the following measurements. Right forearm, $8 \frac{9}{4}$ inches; left forearm, $8 \frac{1}{2}$ inches. Right arm, $9 \frac{1}{2}$ inches; left arm, 94 inches. The hands remain in a position of semiflexion, the fourth and fifth fingers more flexed than the second and third. The finger-portion of the hand is much drawn over to the ulnar side-the thumb is applied against the forefinger. The attitude of the hands is exactly that of Paralysis agitans, but there is no tremor whatever in the fingers. The two distal phalanges appear somewhat overextended upon the proximal phalanx. The intrinsic muscles of the thumb and the interossei appear to be thin.

As you observe, this man can flex and extend his fingers, but the movements are exceedingly slow. He can, in the same deliberate way, flex and extend (though not to the full extent) both elbow-joints, but there is very little capacity for pronation or supination. He can raise his arms straight up into the air and abduct them from his trunk, the shoulderjoints being less affected than the elbows.

There is a very curious circumstance to be noted in connection with the movements of his limbs. In response to my request, he raises his hand or his foot to some distance above his couch, and there he lets it remain for several seconds until, incleed, he is told to drop it; and if I lift one of his limbs, and place it in any position, so it remains in a cataleptic fashion. When told to replace it, it is long before he makes any movement, and then the limb descends slowly. Tho muscles of his trunk appear to be weak; he cannot raise himself in bed, and, indeed, does not move at all-lying, if not disturbed, for hours together in the position in which he is placed.

As regards the lower limbs, they are not so much emaciated as the upper extremities, but the muscles are flabby. He can 
lift either heel very slowly off the couch, can bend either knee, but can only move the ankle-joints a very little. All the joints appear very stiff, and require considerable force to move them.

The patellar tendon-reflex is only just obtained. There is no ankle-clonus. The cutaneous reflex of the foot-sole is obtained on each side.

The right pupil is smaller than the left. They both react to light.

The heart-sounds appear distant; there is no murmur. As regards his mental state, in reply to inquiry he says that " he feels lost." He says " he wants to give his address," and gives 139 Bow Road, which is not altogether correct. He seems very obtuse, and scarcely speaks at all, though he is always apparently conscious.

The faradaic excitability of the muscles of the forearms is normal, that of the arms and lower extremities exhibits a very slight and unimportant lowering.

The action of the rectum and bladder is preserved. He has no difficulty in retaining his urine or fæces, but sometimes a little delay occurs in expelling the contents of the blndder.

There is no disposition towards the formation of bed-sores.

The ophthalmoscope shows no change in the fundus oculi.

These represent the principal symptoms of a condition which is manifestly of an unusual and obscure character. I have been led to conclude that the patient represents an anomalous form of Paralysis agitans, partly by the necessity of excluding other explanations, and partly by the resemblance of the patient's state to that which would be produced by an intensification of certain symptoms of shaking palsy. Let us first see how far his condition can be made to tally with that produced by certain other conditions.

The preserved electric irritability of the muscles enables us at once to exclude, what otherwise might be a not unlikely supposition, that the patient is suffering from a severe form of lead-poisoning. In such a condition the faradaic excitability would be very much reduced, or, still more probably, absent. Progressive muscular atrophy is excluded by the universal character of the lesion. As you are aware, that disease picks 
out groups of muscles physiologically associated in their action, leaving others intact. Here the affection is a general one of the whole muscular system, and, in addition to this, the mental condition, or, at least, the laborious slowness of movement in response to order which we observe in this man, forms no part of the history of progressive mascular atrophy. Bilateral sclerosis, which at first suggests itself, on account of the rigidity of the limbs, is excluded by the condition of the tendon-reflexes, which in that disease would certainly be exaggerated. So also would they be, though not to an equal extent, in Charcot's amyotrophic lateral sclerosis. In both these conditions, the one dependent on sclerosis of the lateral columns alone, and the other upon sclerosis of those columns along with lesion of the large ganglionic cells in the anterior cornua, the tendon-reflexes are intensified. For the same reason, cerebro-spinal insular sclerosis must also be excluded.

On the other hand, let us see what symptoms are to be found which accord with the view that the patient is affected with Paralysis agitans. We have not here, it must be remembered, the opportunity of seeing him walk. That is a great loss, for the attitude of a patient with shaking palsy is, as you have seen, exceedingly characteristic. "The patient," as Charcot says, "loses the faculty of preserving equilibrium whilst walking. In some we notice a tendency to propulsion or to retropulsion;" (in this female, as I showed just now, the tendency to retropulsion when I pulled the skirt of her dress is well marked) "without feeling any giddiness, the patient is in the first case propelled forward and, as it were, compelled to adopt a quick pace; the individual is unable without extreme difficulty to stop-being apparently forced to follow a flying centre of gravity." He adds: " A peculiar attitude of the body and its members, a fixed look, and immobile features should also be enumerated among the more important symptoms of this disease." Again: "The muscles of the face are motionless, there is even a remarkable fixity of look, and the features present a permanent expression of mournfulness, sometimes of stolidness or stupidity."

Although we cannot see this patient stand or walk we have the opportunity of noting the fixed look and immobile 
features which singularly resemble this description, as well as what we observe in the other patient. Might not a widespread softening of the brain be attended with a similar physiognomy? I think it might. But it must be remembered that the mode of progress of the disease in this man does not accord with such a supposition. There is a gradually progressive loss of power and increasing rigidity in his members. When you have widespread atheromatous changes in cerebral arteries leading to thrombosis and softening, the paralysis which ensues, although it may easily involve all the limbs, does so not by slow and imperceptible degrees, but by leaps. A more or less sudden loss of power occurs in one limb, and after an interval of varying duration the same thing happens in regard to another. Moreover in such a case again we should certainly expect the tendon-reflexes to be exaggerated -not lowered in activity as is the case in this man's knees. The same argument applies against the suggestion of the growth of a cerebral tumour, which besides is additionally rendered improbable, though not, it must be allowed, impossible by the absence at any time of pain in the head, and romiting, and the fact that no changes are discernible with the ophthalmoscope. But there are still two other circumstances which, although not absolutely conclusive, speak most strongly against the view that the condition described depends on a destructive intracranial lesion. The patient is able to retain his urine and freces. If his helplessness were dependent upon extensive brain softening, it is in the highest degree improbable that the power over the bladder and rectum would have been maintained. I mention this as a result of clinical experience without being able to say what portion of the encephalic centres must be involved to induce this particular loss of power. It is a fact that in more or less generalised paralysis from cerebral softening we do constantly find that the evacuations cannot be restrained.

The second circumstance is that the patient, though he lies in the position in which he is placed, shows no disposition to the formation of bed-sores. It is true that he was placed on a water-bed as soon as he arrived, but the helplessness which we see had existed for months before his admission into hospital, 
and during that time he did not enjoy this advantage. But besides the expressionless features and fixity of looks, we have here two other symptoms of Paralysis agitans of great importance. The first is the attitude of the fingers which, as you have seen, precisely resembles that which is to be observed in the female patient. Now this attitude is very peculiar. It does not occur in ordinary cases of hemiplegia or generalised paralysis from extensive cerebral softening. In such cases it is true the hand tends to assume a position of more or less strongly marked flexion, but the fingers are also and indeed especially flesed. Here on the contrary the forefinger and middle finger at least tend rather towards an attitude of over-ertension. The phalangeal portion of the hand is besides inclined towards the ulnar side. It was the look of these hands which first suggested to me the idea that the patient might be suffering from Paralysis agitans.

Another symptom is the rigidity. A patient of Charcot's said that his joints appeared "soldered together." Benedikt suggests that the habitual rigidity of a certain number of the muscles undoubtedly contributes in rendering movement laborious.

The muscular rigidity which occurs in Paralysis agitnns seems to me peculiar. It is not apparently a spastic condition like that e.g. which we see in the late rigidity of hemiplegia or in the sequel of myelitis with secondary degeneration of the lateral columns of the cord. It resembles to a remarkable extent the stiffness which results from disuse. You see this condition well marked in the muscles of a forearm which has been for some weeks confined to a splint on account of fracture. The muscles are feeble and stiff, but the stiffiness can be overcome with tolerable ease by passive movements. There is no tension of the muscles in this case any more than there is in the case of the fractured arm, and here, as you see, they are actually flabby. Along with his rigidity, if such it can bo called, is a condition which Charcot has called attention to -a retardation in the execution of movements. The patient performs movements with extreme slowness. "In relation to the faculty of speech," Charcot writes, " there is a comparatively considerable lapse of time between the thought and the aot. 
One might suppose that the nervous influx cannot be set to work until after extraordinary efforts." Probably, also, I would suggest, the faculty of receiving impressions is likewise defective.

The muscular stiffness is commonly most marked in the advanced stages of the disease. Charcot writes: "There are cases, though these are rare indeed, in which muscular rigidity is a symptom of the early stage of the disease, and a really prominent one. I have recently observed an example which belongs to this category. The patient had scarcely noticed the tremor, which, in fact, showed little intensity in his case, and was.confined to one hand. He already displayed, however, in a high degree, the peculiar attitude of the body and its members, the difficulty of movement and the characteristic gait." In a case under the care of Dr. Gowers in this hospital, the patient, a female, exhibited all the symptoms of Paralysis agitans except the trembling, which was barely perceptible. In this man there is an entire absence of tremor. But we do not know whether the symptom has always been absent. It is quite possible that there may have been a certain amount, perhaps too small to attract the patient's attention. However that may be, I do not consider that the total absence of trembling is any bar to our reception of this case as one of Paralysis agitans. The remaining symptoms appear to me to be quite sufficient to enable us to relegate the case to that category. I may remind you of the analogy in this respect with what obtains in another disease of the cerebro-spinal nervous system-tabes dorsalis. The cases are numerous in which the symptom ataxy of gait which gives the name progressive locomotor ataxy to the disense, is entirely absent.

It is very probable that such cases as this man's are not so rare as might be thought. Looking back to past experience, I am disposed to think that I have seen several such in workhonses and hospitals, where they have been classed with cases of softening of the brain.

But the converse to this total absence of tremulousness may be observed. The movements may be so intensified as to occupy almost the whole attention. I lately saw the folluwing case : 
Mrs. M., 64, a farmer's widow (April 2b, 1881): Twentyseren years ago she began to get weak in the right hand, and thirteen years since her head began to shake.

Now as she sits she is constrntly moving all over; her head is jerked, the arms, legs, and body writhing. She is constantly gasping in her breath, her face twitching-in an incessant state of distress. The larynx is prominent, owing to great action of the sterno-mastoids and trapezii. There is, she says, a " distressing feeling in her inside."

She is constantly obliged to be occupying herself. Whilst I examined her she was knitting.

Her daughter says she is better in herself than she was six years ago, but the movements are about the same.

She sleeps about four hours at night.

The general health is good.

She is "never ill." Sho always feels better when by herself. Any nervous excitement increases her distress.

There is constant snorting and sniffing.

Here is an example of another variety :

William W., æt. 64, was admitted into the hospital on May 20, 1878, with Paralysis agitans, which had begun five years previously.

He was an engine-driver who had never had a day's illness in his life. In the course of his work he had to crawl into very hot boilers to clean them out, and to this he attributed his illness.

His symptoms began with subjective coldness of the knees, shortly followed by shaking of the left hand, left leg, and then of the right hand.

There was almost constant shaking of the left hand. If he took hold of an object and held it firmly, the shaking stopped for a fer seconds, but then recommenced worse than ever.

In this man there was a very peculiar condition. Whilst he was at rest there was no shaking of his legs, but if he stood up and attempted to walk, he remained for a time unable to start, his feet, however, beating the ground rapidly. All of a sudden this would cease, and he would start off at a fair pace, though he required some one to hold him up. This "marking time" 
action when he tried to walk had been observed abont eight months. The patient, who was an engine-driver, appeared much struck with Mr. Broster's suggestion, that it reminded one of the wheels of a locomotive failing to bite the rails when they are slippery with frost, and making, in consequence, ineffective revolutions.

Paralysis agitans is sometimes acute in its progress, and this, I think, is more often the crse when the patient is comparatively young. I lately saw a man, æt. 38, whose symptoms dated from on $\theta$ year only. They had commenced with hesitation of speech, which was followed by shaking, first of the left and then of the right arm, and when he came to $\mathrm{m} \theta$ he presented all the symptoms in a marked degree.

There was a patient in the hospital, a year or two ago, who was still younger. I gather the following account from Mr. Broster's notes, taken on his admission :

Benjamin L., æt. 22, was admitted into hospital on April 30, 1879. His occupation is that of a butcher, and for five years past he has been in London, having previously lived in the country. He looks about his age. Somewhat apathetic in manner, he yet complained of irritability of temper, especially when exposed to noise. His memory is good. He has no headache nor giddiness. The speech is thick, and somewhat indistinct; the articulation being hurried, and the words run together. The tongue showed marked tremor. Saliva dribbled from his mouth at times. There is difficulty in swallowing, and he is obliged to have his food chopped up fine.

His face wears a fixed look. He cannot frown, and can only show his teeth feebly by roluntary movement. During involuntary movement, on the other hand, as when he laughs, he shows them very well. He has no emotional instability. As he sits, there is marked shaking of the head and upper limbs. The arms-especially the right arm-are in a continual state of rather violent agitation, which is increased by excitoment, and is least when he is left quietly to himself. There are also involuntary uniform movements of the legs and feet when he is seated. If he lifts his heel off the ground, so as to rest solely on the ball of the foot, there is a rapid movement similar to foot-clonus. No foot-clonus can be elicited 
by sudden passive dorsal flexion of the foot. The patellar tendon-reflex is normal-free from exaggeration. In his walk he inclines forward, and "scuffles" along, but not so hurriedly as is often seen in these cases. He complains of stiffness in his arms and legs.

When he picks up anything with either hand there is a momentary lull in the movement, and he takes hold of them quietly and steadily. Immediately afterwards the movements recommence. $\mathrm{H}_{\theta}$ is very easily pushed forwards or backwards, however much he may try to resist this.

His breathing is of a half-sobbing character.

There is slight lateral curvature. No spinal tenderness.

Now, in this case, it was only eleven months before these notes were taken that the patient had first noticed a slight shaking of the right hand. This very gradually increased, and in three months he was forced to give up his occupation. Two months later he noticed that his left hand was beginning to shake like the right, and after two or three months more his legs also became involved. There was shaking whilst he sat, and he says that they shook all the more if he bore his weight upon his toes. A month or two after this, his swallowing became affected, and his mouth, according to his account, was always full of saliva About the same time his articulation became embarrassed.

This man acknowledged a course of life of the most dissipated character. He had lived freely and drunk heavily. From the age of 16 to 21 he had masturbated two or three times a day ; and from 21 to 22 , about the time of the commencement of his symptoms, had indulged to the greatest excess in sexusl intercourse. He had never had syphilis, but bad once suffered from gonorrhoer. The family history was a healthy one.

It is worth noting that, in the other case-patient aged 38 -there was a history of excessive sexual intercourse immediately preceding the commencement of the symptoms.

The patient, William V., who is now attending the hospital, is affected with shaking palsy, which commenced in his left arm. By the dynamometer, the grasp of the right hand measures 50, that of the left 40.

The movements in. this case are of a somerwhat unusual 
charncter. They are much larger in extent than is commouly seen, so that, as the patient sits he flaps his knees with both hands noisily and roughly. His legs also are affected with coarse movements. His walk is characteristic, the body being bent forward, and the head maintaining a "set" position.

If we ask him to pick up a pen off the table, his arm is still whilst he is stretching it out to grasp the object; but when the hand closes upon it the movements begin to recur with grent energy.

Another of our out-patients, a female, presents symptoms which are at first strongly suggestive of this disease, but I do not think she is an example of it.

Elizabeth B. is a widow, 66 years of age, who was strong and well, and had nothing to complain of till ten weeks ago, when she woke up one morning retching and vomiting, and found that she had lost power to a certain extent in the left arm and leg. She found that she could not keep her arm still, and her leg also was constantly shaking. A very aged neighbour who came to her, said, " Don't touch me, or yop'll pull me down," the shaking was so violent. She knocked the left knee against the right so violently that it was quite bruised. She remained in bed three weeks, during which the movements were very violent, but afterwards they became less so.

Now, we observe that as she rests her hand on her knee it is steady, but when she tries to pick up things from the table there are rhythmical movements-flexion and extension movements of the hand numbering about 180 in the minute. The attitude of the hand is not that of Paralysis agitans. A friend who comes with her says that she is sometimes obliged to throw the bed-clothes off, she complains so much of hent. Since she has been here before us, her face has come over in a red flush several times.

The wrist-reflex is exaggerated on both sides, but especially on the left, whilst the patellar tendon-reflex approaches to a clonus on the left, and is in some excess also on the right side. She walks with short toddling steps, and is compelled to use a stick, otherwise she falls. The left knee never shakes now, but 
sometimes in walking it "catches up." The dynamometer shows a grasp of $40^{\circ}$ with the right, $22^{\circ}$ with the left hand.

She has never had any numbness in the left hand, but there is often aching pain in the forearm, especially towards night.

We do now and then observe a state of tremor in the paralysed limbs of a hemiplegic patient; but so far as I have seen, it is very rare to find such an amount of tremulons movement as we se $\theta$ in this woman. Here the tremors closely resemble those of Paralysis agitans, and the case might easily be mistaken for one of that disease.

According to Nothnagel, the condition has been observed in connection with lesion in the following localities:-1. The internal capsule in its posterior segment. 2. Optic thalamus. 3. The foot of the corona radiata. In these situations it is, he points out, that lesions are most apt to be accompanied by hemichorea and athetosis, with which it is supposed these tremors are nearly allied. It is not certain whether the condition occurs as a result of cortical lesions.

This patient evidently had a sudden cerebral attack, accompanied by romiting and loss of power, in the arm and leg of the left side. In the suddenness of its origin, the disease contrasts as strongly as possible with shaking palsy.

The exaggeration of reflex amounting to foot-clonus on the affected side, is also opposed to the diagnosis of that disorder. The attack has, probably, been of an apoplectic character, the exact situation of which, however, I am not prepared to indicate with any confidence.

Passing over the morbid anatomy of Paralysis agitans, about which nothing conclusive is as yet established, I would refer to one or two points in regard to the symptoms.

If wo examine the upper extremity in a case of true shaking palsy, we are struck at once by the circumstance that apparently the small muscles, those concerned in the most delicate movements, are those which suffer most. The attitude of the fingers is that which would be produced by alternate contraction and relaxation of the fibres of the interosseous muscles. It is unusual in other conditions to find predominance of affection of such muscles over the larger ones. In the climax of an epileptic seizure the hand is clenched. 
The contraction of the large and powerful flexor muscles lying on the anterior surface of the forearm, overpowers completely that of the small interossei. So also in the converse of convulsion-in hemiplegia, when the paralysis is complete the fingers lie passively in an attitude of semiflexion. There is only one condition, I think, in which the position of the fingers at all resembles that which they occupy in shaking palsy, and that is the singular disorder called Tetany. It is not easy to see any kind of association between these disorders, but the point is perhaps worth noting.

As regards the piping senile voice, to which I have already referred, I have lately met with an instance in private practice which has afforded me an opportunity of investigation. The patient, William B., aged 57, has the characteristic fixed look and the piping voice. His right hand, ever and anon, but not coustantly, is shaken to and fro. The left also is shaken, but much less. He feels very weak in the right arm, and says that he has scarcely any use at all in it.

He does not $\operatorname{com} \theta$ over in flushes of heat or perspiration.

Sometimes, he says, he can scarcely talk. This, he thinks, is owing to something in the throat. His wife has noticed the alteration in the voice.

About two years ago he began to feel loss of power in the right arm-that hand would drop occasionally from the wrist so that he could not depend upon holding things. The loss of power has gradually increased, especially of late. Within the last few weeks he has inclined to trip with the right leg, which feels, as it were, shorter than the other.

Lately, for a fortnight past, he has been liable to giddiness, and on one occasion he nearly fell down.

He does not suffer from sickness. He has usually had good health. His appetite is good; he sleeps well; the bowels act.

$\mathrm{He}$ has a difficulty in holding his urine, and would wet himself if he were not very quick. He gets up two or three times in the night to pass water-just a little.

Memory is good. He would rather be by himself, and avoids noise and company. There is a fixed look of the face with half a frown upon it, and the head is held stiffy, the eyes usually looking straight in front. 
The tendon-reflex at the wrist is equal on both sides, and not abnormal.

At my request Dr. Felix Semon was good enough to examine this patient with the laryngoscope. His report is that there is neither motor nor sensory paralysis nor loss of reflex-sensibility to be detected in either pharynx or larynx, and that both these parts are quite free from traces of previous specific or other disease. It seems probable, therefore, that the high tone, the piping roice, which I have likened to that adopted by an actor who represents adranced age upon the stage, may be dependent upon a functional imperfection of the soft palate, perhaps due to a vibratile condition of its muscular structure. 